\title{
Adsorption mechanism, secondary structure and local distribution of proteins at polyelectrolyte brushes
}

\author{
Claus Czeslik ${ }^{1}$ (D) Alexander Wittemann ${ }^{2}$ (D)
}

\begin{abstract}
In many biomedical and biotechnological applications, proteins are immobilized at aqueous-solid interfaces. Generally, an adsorption-induced denaturation of the proteins has to be avoided, because it prevents the use of their biological activity or it might cause adverse effects in living organisms. Furthermore, control over the degree of protein adsorption including protein desorption is extremely useful. Over the recent years, polyelectrolyte brushes have been examined in terms of protein adsorption, and the majority of the studies document their biocompatible properties. Moreover, they show a variable protein affinity responding to the ionic strength of the protein solution. In this short review, selected studies are highlighted that illustrate the most significant properties of polyelectrolyte brushes as adsorbent interfacial structure for proteins.
\end{abstract}

Keywords Protein $\cdot$ Polyelectrolyte brush · Adsorption $\cdot$ Secondary structure $\cdot$ FTIR spectroscopy

\section{Introduction}

In various medical applications, biological liquids and tissues are exposed to artificial interfaces, for example, when using contact lenses, dental implants, or stents [1-4]. Then, the initial adsorption of proteins at these interfaces can induce the formation of biofilms, which can in turn cause irritations and inflammations of the human body [5-7]. To increase the biocompatibility of artificial interfaces, surface modifications are helpful that suppress the spontaneous adsorption of proteins, for example, by grafting poly(ethylene glycol) [8], glycopolymers [9], fluoropolymers [10], or zwitterionic polymers [11] to the solid support. On the other hand, various biotechnological applications require efficient binding of proteins to interfaces of solid supports without losing the native properties of the proteins $[12,13]$. This can be accomplished

Alexander Wittemann

alexander.wittemann@uni-konstanz.de

Claus Czeslik

claus.czeslik@uni-dortmund.de

1 Fakultät für Chemie und Chemische Biologie, Technische Universität Dortmund, Otto-Hahn-Str. 4a, D-44227 Dortmund, Germany

2 Colloid Chemistry, Department of Chemistry, University of Konstanz, Universitaetsstrasse 10, D-78464 Konstanz, Germany by grafting hydrophilic polymers to these interfaces, thereby creating a brush topology [14-16]. Polymer brushes often provide control over the degree of protein adsorption, if a stimuli-responsive polymer is used (Fig. 1).

For example, brushes made of poly(Nisopropylacrylamide) show some temperature sensitivity and a concomitant change of protein affinity [15, 17-19]. Moreover, using weak polyelectrolytes, changing the $\mathrm{pH}$ value will alter the charge density of the polyelectrolyte brush and also the degree of protein adsorption, if electrostatic interactions prevail $[20,21]$. Remarkably, the ionic strength of a protein solution can also affect the protein affinity of a polyelectrolyte brush [22-24]. This phenomenon has been reported for poly(acrylic acid) (PAA) brushes in many studies. At low ionic strength, considerable amounts of proteins can be adsorbed at PAA brushes, whereas the release of the adsorbed proteins can be triggered by increasing the ionic strength of the solution to a few hundred $\mathrm{mM}[25,26]$. The underlying mechanism of adsorption has been discussed in the literature over some years and will be addressed in this short review. Furthermore, the structure and biological activity of proteins embedded in polymer brushes are of fundamental interest, because they are the key parameters for the potential application of the brushes in biotechnology. Thus, selected studies analyzing the secondary structure of proteins in a polyelectrolyte brush will also be reviewed here. 


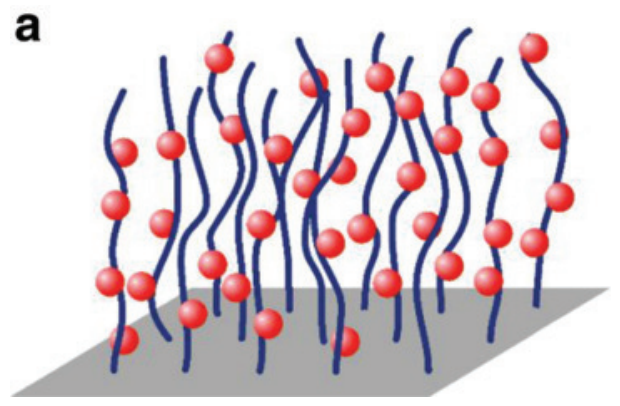

Fig. 1 Surface-anchored polymer brushes can provide control over surface interactions with proteins: (A) Polymer brushes may take up large amounts of protein, which is incorporated between the polymer chains. (B) Depending on the nature of the polymer, polymer brushes

The investigation of the structure, dynamics, and activity of adsorbed proteins at aqueous-brush interfaces can be carried out applying several methods, which are well established in the biosciences. A few of these methods will be listed here to address readers not familiar with proteins. High-resolution structures of proteins are generally obtained by applying Xray crystallography or multidimensional nuclear magnetic resonance (NMR) spectroscopy [27-29]. However, these methods are not suitable so far to study proteins in polymer brushes, because high-quality crystals, as required for X-ray crystallography, cannot be produced. Also, the complexity and size of the protein-laden polymer brushes make the interpretation of NMR spectra rather difficult. Hence, highresolution techniques are not generally feasible, which has stimulated continuous development of many powerful lowresolution techniques. To analyze the secondary structure of proteins, free in solution or adsorbed at colloidal particles, circular dichroism (CD) and Fourier transform infrared (FTIR) spectroscopy are the methods of choice [30-32]. The latter can also be applied to study planar interfaces utilizing the attenuated total reflection (ATR) mode. The determination of the secondary structure elements and their relative fractions by CD and FTIR spectroscopy is achieved via reference spectra [33-37]. In FTIR spectroscopy, the amide I band, located at 1700-1600 $\mathrm{cm}^{-1}$, can be decomposed into sub-bands that can be assigned to particular secondary structure elements (Fig. 2). Similarly, experimental CD spectra of proteins can be regarded as superposition of spectra associated with the various secondary structure elements of the protein.

To assess the tertiary structure of proteins and their native activity, such as conformational changes upon ligand binding and enzymatic conversion of substrates, various fluorescence techniques have been established [38-43]. There are also surface-sensitive methods, such as the total internal reflection fluorescence (TIRF) spectroscopy [44]. Although crystals of protein-laden polymer brushes are not available, scattering of X-rays and neutrons still provides essential structural information about protein-laden polymer brushes, in colloidal

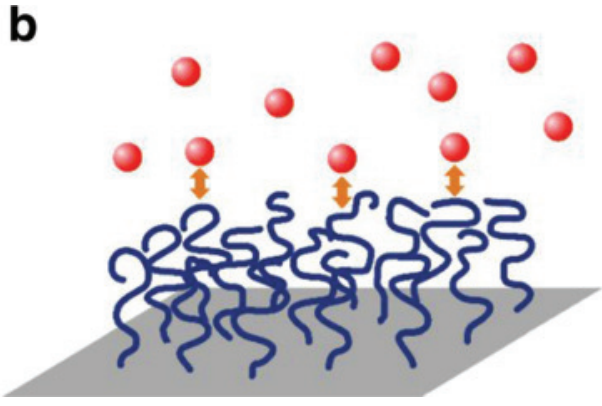

can also serve as protein-resistant surface. Using stimuli-responsive polymers, the degree of protein loading can be controlled between (A) and $(\mathrm{B})$ by varying the ionic strength, the $\mathrm{pH}$ value or the temperature

solutions and at planar interfaces [45-47]. Scattering length density profiles are obtained from these methods showing the distribution of proteins inside the polymer brush. Direct visualization of protein adsorption at polymer brush particles is achieved applying confocal laser scanning fluorescence microscopy [48], atomic force microscopy (AFM) [49], and cryogenic transmission electron microscopy (cryo-TEM) [50], among others.
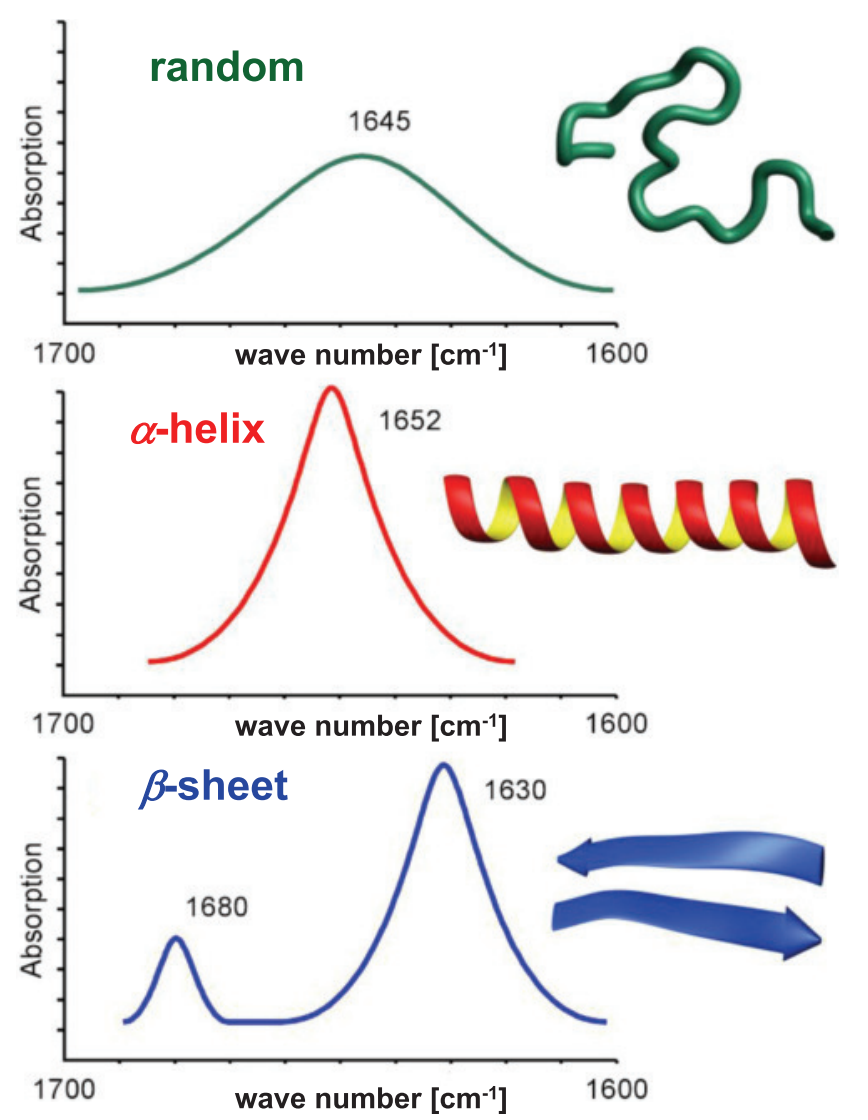

Fig. 2 Schematic representation of the IR absorption of typical secondary structure elements of proteins in the amide I region. The shape of the experimentally obtained protein amide I band depends on the contribution of these elements. Reproduced with permission from Bruker Optics Ettlingen, Germany 
There are many studies in the literature that report on conformational changes of proteins that adsorb at various aqueous-solid interfaces documenting the importance of the careful characterization of adsorbed proteins, when these shall be used in biomedical or biotechnological applications [51-54]. Notably, adverse effects on the native structure of a given enzyme can be caused by the interaction with the supporting surface, thereby hampering severely its activity $[55,56]$. Moreover, from an academic point of view, the detailed understanding of protein adsorption mechanisms is of utmost importance. In this short review, we will limit these aspects to polyelectrolyte brushes that have turned out to be a promising interfacial structure for protein immobilization.

Polyelectrolyte brushes can be realized in spherical or planar geometries. In both cases, long polyelectrolyte chains are bound to a solid support, a poly(styrene) bead, as shown in Fig. 3, or a poly(styrene) film, with a high grafting density that limits the conformational freedom of the chains. The preparation of spherical polyelectrolyte brushes (SPB) has been carried out by surface-initiated polymerization of water-soluble monomers, such as acrylic acid or sodium styrene sulfonate $[57,58]$. Because of this preparation route, the SPB exhibit well-defined core-shell morphologies. This was experimentally shown by scattering techniques such as SAXS, ASAXS, and DLS [59]. Alternatively, planar polyelectrolyte brushes have been prepared by transferring diblock copolymers, such as poly(styrene)-poly(acrylic acid), onto a poly(styrene) film using a modified Langmuir-Schäfer technique. The poly(styrene) film can be deposited on various supports, such as silica wafers or quartz prisms, depending on the method applied to study these interfacial structures [60].

Adsorption of proteins at spherical or planar polyelectrolyte brushes ("polyelectrolyte-mediated protein adsorption," PMPA) is usually observed, when the packing of the chains is

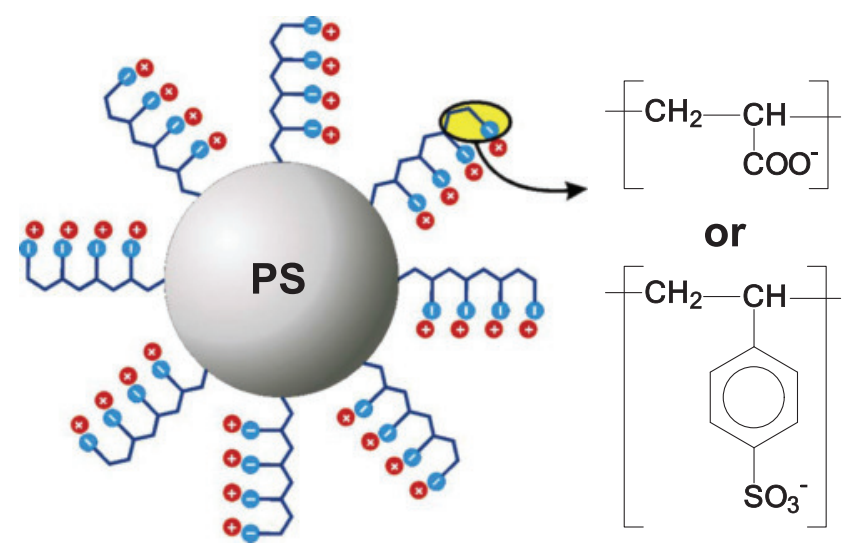

Fig. 3 Schematic representation of spherical polyelectrolyte brushes (SPB) for the adsorptive immobilization of proteins. Long chains of poly(acrylic acid) or poly(styrene sulfonate), among others, can be densely attached to narrow-dispersed polystyrene (PS) particles. Adapted with permission from Ref. [81]. Copyright 2004, American Chemical Society sufficiently dense, i.e., the dimensions of the chains must be much larger than the distance between two neighboring chains $[59,61,62]$. A remarkable characteristic of these brushes is the almost complete entrapment of counterions within the brush layer. The high osmotic pressure thus created within the brush determines the structure and the properties of the brushes in solution, such as their interaction with proteins [59].

\section{Adsorption mechanism of proteins at polyelectrolyte brushes}

Figure 4 schematically summarizes the uptake of proteins by and the release of proteins from polyelectrolyte brushes. Interestingly, SPB that possess poly(acrylic acid) (PAA) chains strongly adsorb proteins, if the ionic strength is low regardless of the net charge of the protein molecules [23]. The amount of protein varies largely linearly with the concentration of protein in solution. With increasing ionic strength, the brush layer becomes more and more protein-resistant [23, $24,61]$. In this regime, the steric repulsion between the

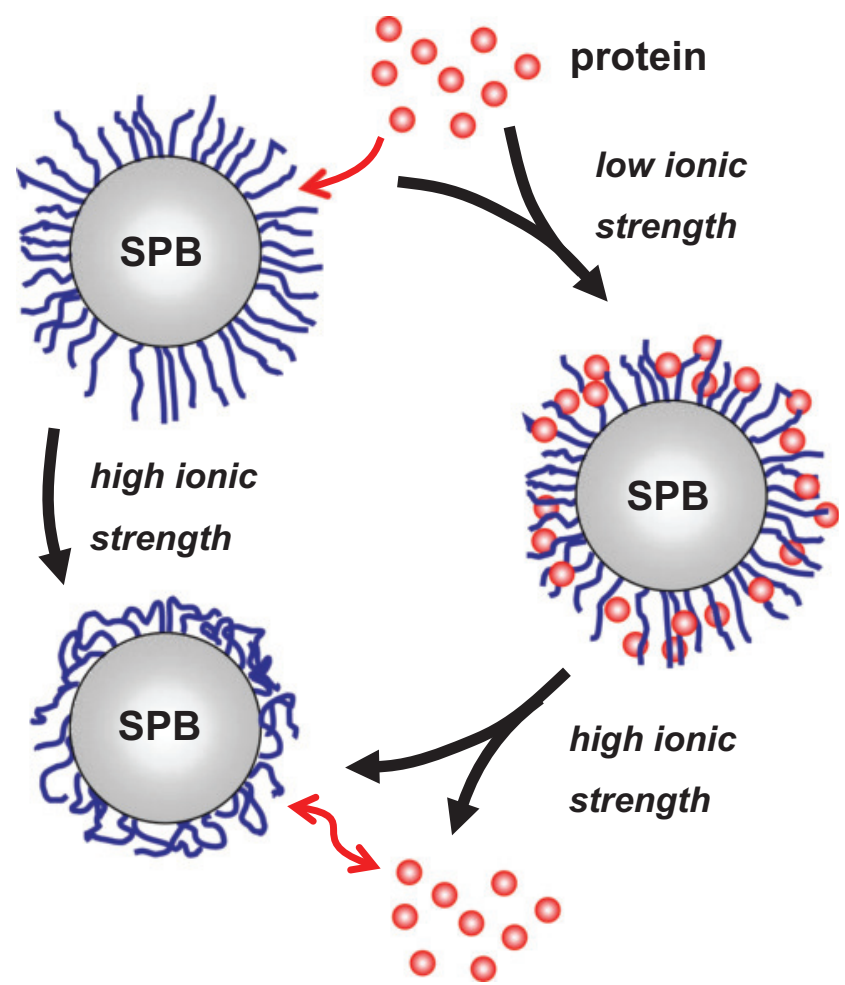

Fig. 4 Polyelectrolyte-mediated protein adsorption (PMPA): Large amounts of proteins can be adsorbed onto particles bearing dense spherical polyelectrolyte brushes (SPB) by direct uptake from the solution without impeding the excellent colloidal stability brought by the attached polyelectrolyte chains. Protein uptake into the brush layer only occurs at low ionic strengths, whereas proteins are repelled at ionic strengths higher than $0.1 \mathrm{M}$. Moreover, proteins bound at low ionic strength can be quantitatively re-liberated by raising the ionic strength. Hence, the SPB can reversibly be loaded with protein molecules. Adapted from Ref. [61] with permission from the PCCP Owner Societies 
dissolved proteins and the brush layer of the SPB becomes operative, so that only marginal adsorption takes place. Therefore, it is possible to release proteins bound at low ionic strength by gradually increasing the ionic strength to a few $100 \mathrm{mM}$ (Fig. 4) [23].

When positively charged proteins adsorb at a negatively charged polyelectrolyte brush, there are favorable Coulomb interactions that drive this adsorption. In addition, both the protein and the brush will release some of their counterions which represents an additional entropic driving force. However, even proteins with a negative net charge adsorb at a PAA brush. Model calculations have shown that, as long as the negative net charge of the protein is not too high, a charge reversal of the protein inside the brush can take place due to a lowered $\mathrm{pH}$ value [63-65]. Then, the protein adopts a positive net charge inside the brush and will again interact with the PAA brush via favorable Coulomb forces. However, this charge reversal cannot be assumed as the dominant driving force for adsorption, when proteins with a higher negative net charge adsorb at a PAA brush, such as BSA at $\mathrm{pH}$ 7, two $\mathrm{pH}$ units above its isoelectric point. Hence, a different mechanism has been proposed which is mainly based on the entropy gain upon the release of counterions [61, 66-68]. The main requirement for this explanation is the presence of positively charged patches on the surface of the protein (Fig. 5). The charged patches have to be of a minimum size to ensure strongly associated counterions, because a single charge on the surface cannot confine its counterion, and there would be no net interaction upon putting the protein into the brush layer. However, patches of several charges will bind their counterions more strongly and become multivalent counterions in turn, when the protein is embedded into the brush layer. As a consequence, positive counterions previously immobilized within the brush layer as well as an equal number of negative counterions formerly associated with the protein in solution are released (Fig. 5). On the other hand, the negative charges on the surface of the protein carry along their positive counterions which will further increase the number of small ions within the brush layer. The balance between release and uptake, however, is positive. This results in the lowering of the osmotic pressure within the brush layer. The gain in entropy by the release of counterions was measured by isothermal titration calorimetry (ITC) [69, 70]. This analysis demonstrated that the PMPA can be driven by a gain in entropy while the enthalpy increases, which is in full accord with the mechanism of counterion release. It is remarkable that a cancelation of enthalpy and entropy is coupled with the PMPA [70]. A detailed theoretical description of the PMPA is given in Refs. $[66,67]$. Moreover, the central findings of the PMPA were reviewed in Ref. [26].

Further experimental support for the abovementioned adsorption mechanisms of proteins at PAA brushes has been provided in recent high-pressure studies [71, 72]. Pressure favors any process that is accompanied by a volume reduction of the system. The majority of proteins undergoes conformational changes and even unfolding in the pressure range of 5$10 \mathrm{kbar}$ due to the penetration of water into cavities, whereas, in the lower pressure region, up to $2 \mathrm{kbar}$, pressure effects on electrostatic interactions and the hydration of protein side chains play an important role $[73,74]$. Thus, as an important process in aqueous solution, the dissociation of ionic bonds and the subsequent hydration of the separated charges is known to proceed by a volume reduction [73, 74], which can be estimated to about $-10 \mathrm{~mL} \mathrm{~mol}^{-1}$ of generated charges [75]. Thus, ionic bonds can be dissociated by pressure, which is observed in the pressure range up to 2000 bar. Indeed, applying neutron reflectometry, the degree of adsorption of positively charged $\alpha$-chymotrypsin at a negatively charged PAA brush could be reduced by increasing the pressure, because the ionic bonds between the protein and the brush are dissociated by pressure (Fig. 6a, reverse direction) [71]. In contrast, holo-calmodulin has a negative net charge at $\mathrm{pH} 7$
Fig. 5 Counterion release during uptake of a protein molecule into a brush composed of polyanions: above its isoelectric point, the net charge of the protein is negative, but there are always positively charged surface patches. These will act as multivalent counterions of the brush chains leading to a release of confined monovalent counterions upon protein adsorption. This lowers the osmotic pressure in the brush and raises the entropy of the system, which serves as the main driving force for the PMPA. Adapted from Ref. [61] with permission from the PCCP Owner Societies

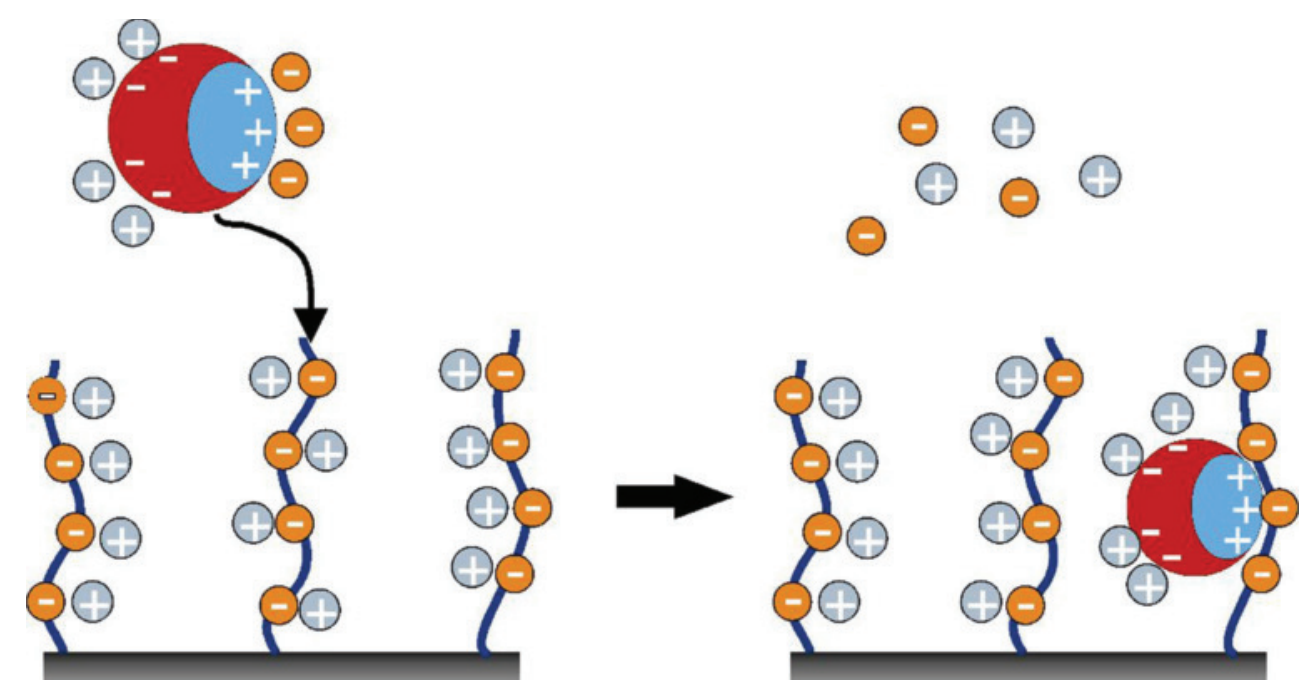


Fig. 6 Volume changes upon interaction of a protein with polyelectrolyte chains, charge reversal and counterion release. The formation of new charges (ions) and the subsequent hydration is known to lower the volume. Reproduced from Ref. [72] with permission from Elsevier

\section{a protein-polyelectrolyte complexation}

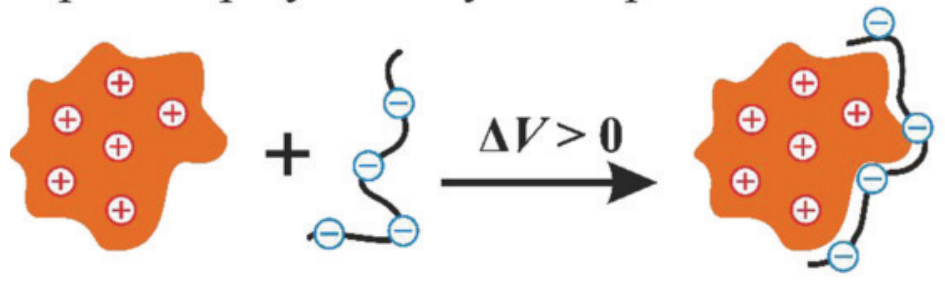

b charge regulation

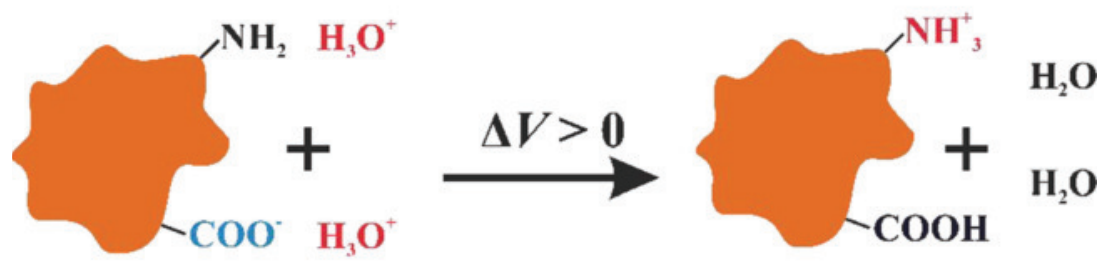

\section{c "condensed" counterion release}

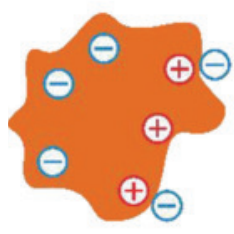

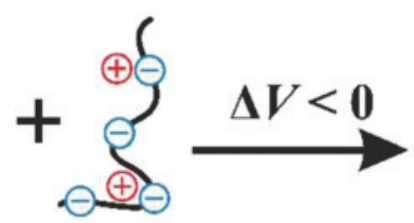

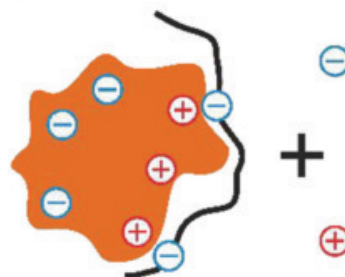

$\oplus \oplus$

(the isoelectric point is 4.6). Remarkably, a pressure-induced increase of the degree of adsorption of holo-calmodulin at a PAA brush has been reported recently in a TIRF spectroscopy study [72]. It has been argued that this experimental observation is in conflict with a charge reversal mechanism for protein adsorption, because a charge reversal of a protein from negative to positive is associated with a volume increase (Fig. 6b). However, the formation and subsequent hydration of free ions upon protein adsorption, as proposed in the counterion release mechanism, is in line with a volume reduction (Fig. 6c). Thus, the observed pressure-driven adsorption of negatively charged holo-calmodulin at a like-charged brush can only be explained by a release of counterions. Evidently, the release of hydrated counterions is associated with a liberation of water molecules. This is reflected by the volume reduction observed in the pressure-dependent studies. Whether and how far liberation of water molecules facilitates the PMPA need to be clarified by further investigations.

\section{Microscopic visualization of protein-laden spherical polyelectrolyte brushes}

The adsorption of proteins at SPB has been visualized using various microscopic techniques, such as atomic force microscopy (AFM) [49], confocal laser scanning fluorescence microscopy [48], and cryogenic transmission electron microscopy (cryo-TEM) [50]. In Fig. 7, selected micrographs are shown that document the effect of ionic strength on the degree of protein adsorption and the brush structure. Using a fluorescent protein, the strong adsorption of the protein at low ionic strength is clearly visible (Fig. 7b). Only little fluorescence is left, when the protein is desorbed from the SPB upon increasing the ionic strength of the solution (Fig. 7c).

A visual impression of the core-shell morphology of SPB can be obtained by AFM. In this case, the polyelectrolyte corona of the particles shows a hit-stick behavior on an oppositely charged support, so that the polyelectrolyte layer cannot retract [49]. The phase-sensitive detection in AFM analysis is able to directly visualize the corona surrounding the colloidal support. It is clear that the strong electrostatic interaction with an oppositely charged support comes along with a distortion of the geometry of the brush. For this reason, the morphology of the brush particles was also explored by cryo-TEM (Fig. 7d-f) [50]. This technique allows for the observation of colloids that are not fixed in any way, showing them in their native environment. Minute amounts of SPB suspensions are spread onto electron microscopy grids. The specimens are transferred to a frozen-hydrated state by rapid vitrification in liquid ethane. While maintaining the specimens at liquid nitrogen temperature, they are introduced into the high-vacuum of the electron microscope column. Because a layer composed 

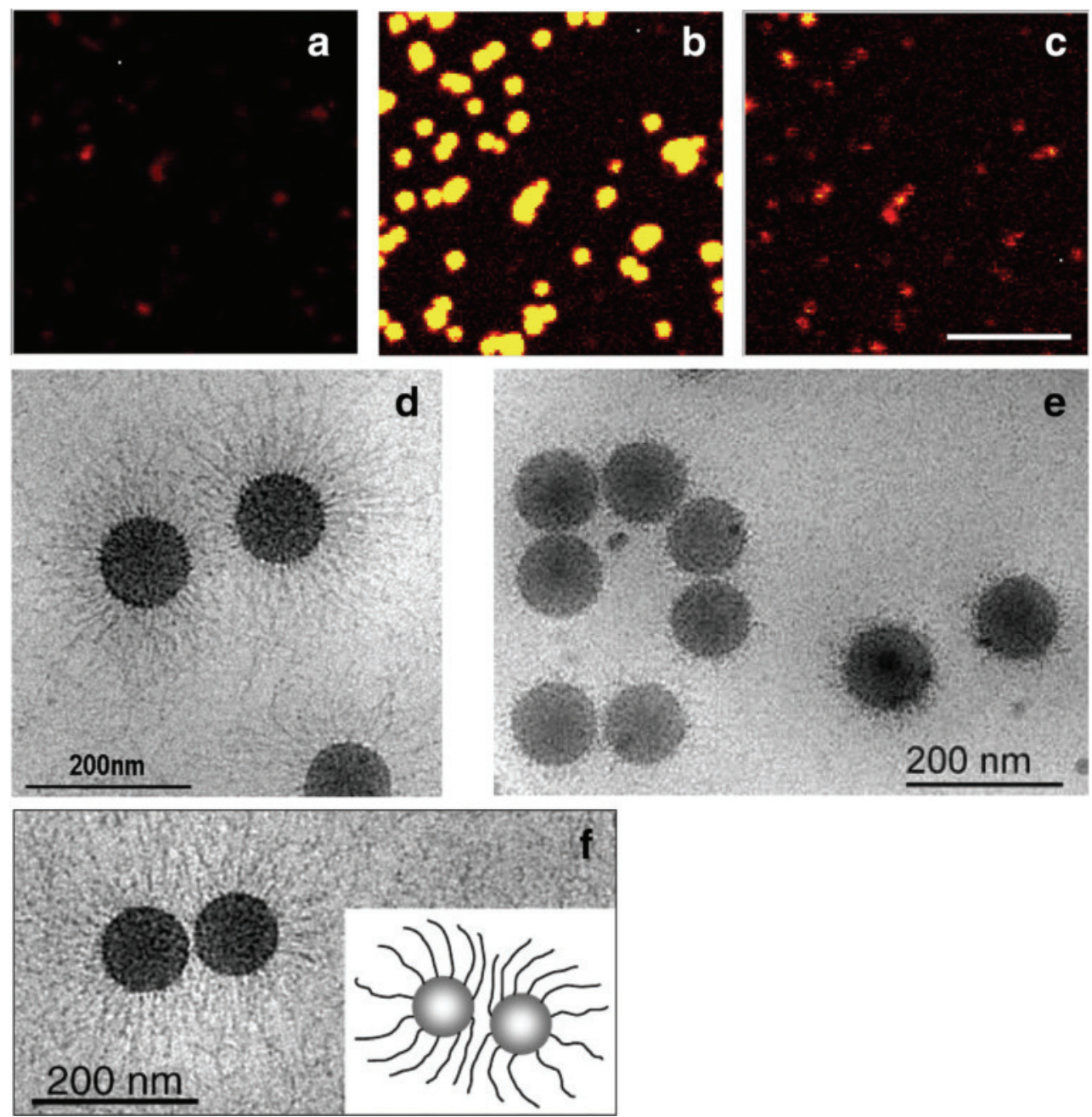

Fig. 7 Microscopic visualization of SPB. a-c: Confocal laser scanning fluorescence micrographs demonstrating the reversible uptake of a fluorescent protein (mEosFP) onto SPB [48]. SPB without protein are barely visible because of their poor autofluorescence (a). SPB in the presence of the fluorescent protein at low ionic strength exhibit strong fluorescence and indicate marked binding of the protein (b). Fluorescence emission decreases to $<1 \%$ after exposure to high ionic strength, indicating efficient release of the protein $(\mathbf{c})$. d-f: Cryo-TEM micrographs of vitrified suspensions of SPB [50]: At low ionic strength $(7 \mathrm{mM})$, the huge osmotic pressure of the confined counterions leads to

of single polyelectrolyte chains is extremely radiation sensitive, the specimens were imaged applying a reduced-dose technique. The low temperature presents an additional protective factor against radiation damage. It is evident that the resolution of cryo-TEM is not sufficient to monitor individual polyelectrolyte chains. However, we could monitor bundles of polyelectrolytes that result from frozen fluctuations of chain density within the brush. Moreover, we could enhance the contrast by replacing the sodium counterions of the polystyrene sulfonate chains by cesium ions [50].

As mentioned above, large amounts of proteins, such as bovine serum albumin (BSA), can be entrapped within the brush layer. Oppositely charged patches on the protein act as strongly stretched polyelectrolyte chains (d), whereas the chains are coiled at high concentration of added salt $(507 \mathrm{mM})(\mathbf{e})$. When two SPB approach each other, a distortion of the brush layer results, which seems to be associated with back-bending of the polyelectrolyte chains (f). The contrast along the chains is enhanced by cesium ions and BSA molecules, which are adsorbed in close correlation to the polyelectrolyte chains. a-c: Reproduced with permission from Ref. [48]. Copyright 2005, American Chemical Society. d-f: Reproduced with permission from Ref. [50]. Copyright 2005, American Chemical Society

multivalent counterions for the brush layer, which leads to close correlation of the protein molecules and polyelectrolyte chains. Indeed, the excellent contrast of BSA in TEM provided a breakthrough in contrast enhancement [50]. The polyelectrolyte chains are clearly visible in the micrographs (Fig. 7d). Moreover, the thickness of the brush layer is close to the value known from DLS, even though DLS is governed by the longest chains of the brush [58]. At low concentrations of added salt, the ionic strength inside the brush exceeds the ionic strength outside the brush, because of the confined counterions within the brush layer [76]. The osmotic pressure created by the confined counterions creates a huge osmotic pressure, which in turn results in a marked stretching of the 
polyelectrolyte chains (osmotic brush) [59]. This effect is well understood from theoretical considerations and was proven experimentally by both scattering experiments and direct measurements of the osmotic pressure of the counterions [59]. However, the cryo-TEM micrographs provided for the first time a direct visual proof of the strongly stretched chains.

At high concentration of added salt, the brush resembles a neutral polymer brush, because the ionic strength inside and outside the brush layer are similar (salted brush) [59]. CryoTEM micrographs reveal an almost collapsed polyelectrolyte layer at high salt conditions (Fig. 7e). Hence, cryo-TEM presents a straightforward method to study the properties of the SPB in solution. Remarkably, many configurations were found where two or more SPB were close together (Fig. 7f). In this regard, the study contributed to an interesting question that is central to a fundamental understanding of steric repulsion. Van der Maarel and co-workers wondered if the polyelectrolyte chains bend back upon approaching or interdigitate [77]. The same question was also examined by Matsen [78]. While van der Maarel and co-workers concluded from their experiments that the chains will interdigitate, Matsen predicted that the chains are tilted outward the zone of maximum compression. A retraction of the chains was also predicted by Ballauff and co-workers [79]. This is in accord with the cryo-TEM micrographs, which support back-bending of the polyelectrolyte chains (Fig. 7f).

\section{Secondary structure analysis of proteins embedded in polyelectrolyte brushes using FTIR spectroscopy}

FTIR spectroscopy has become a routine technique for secondary structure analysis of proteins in solution [30-32]. However, in contrast to CD spectroscopy, this technique was hardly applied to the study of adsorbed proteins so far. Protein solutions are often prepared in $\mathrm{D}_{2} \mathrm{O}$ to avoid strong IR absorption of $\mathrm{H}_{2} \mathrm{O}$ in the amide I band region of the protein. It must be born in mind that $\mathrm{D}_{2} \mathrm{O}$ might alter the secondary structure of a given protein. Also, limited accuracy can arise in the analysis of protein/ $\mathrm{D}_{2} \mathrm{O}$ IR spectra when pattern recognition methods are used [30]. These problems can be remediated by recording protein IR spectra in $\mathrm{H}_{2} \mathrm{O}$. The strong absorption of IR light by $\mathrm{H}_{2} \mathrm{O}$ molecules has to be circumvented by a small path length of the sample cell, which is typically 6-7 $\mu \mathrm{m}$ [80]. For comparison, typical path lengths in $\mathrm{D}_{2} \mathrm{O}$ are $50 \mu \mathrm{m}$. Hence, the small path length must be compensated by a quite high concentration of protein for a meaningful analysis, at least $5 \mathrm{mg} \mathrm{mL}^{-1}$. This high value explains the limited number of FTIR studies on adsorbed proteins. Although colloidal carriers provide large adsorbent surfaces, their diameter should not much exceed the diameter of the protein molecules to ensure such a high concentration, which in turn complicates the separation of non-adsorbed free proteins from the loaded nanoparticles. However, it is feasible to study proteins that are adsorbed at SPB particles by FTIR spectroscopy. As main advantage, the SPB provide a large protein binding capacity, because the proteins are dispersed within the polyelectrolyte brush layer (Fig. 1). As discussed below, scattering techniques like small-angle X-ray scattering (SAXS) and neutron reflectometry clearly show a close correlation between an adsorbed protein and the polyelectrolyte chains.

A series of proteins (Fig. 8) was studied by FTIR spectroscopy, while the proteins were adsorbed at a PAA brush [81, 82]. In the case of SPB, transmission mode FTIR spectroscopy was applied, whereas ATR-FTIR spectroscopy was used for planar PAA brushes. For comparison, solution spectra were also recorded. Generally, very smooth spectra can be obtained after background subtraction, with the amide I band as the dominant feature (Fig. 9). The amide I band mainly reflects the $\mathrm{C}=\mathrm{O}$ stretching vibration, whereas the amide II band contains the N-H bending vibration of the peptide bonds in the protein molecules. As outlined in the introduction, different sub-bands, which can be assigned to the various secondary structure elements, contribute to the amide I band. The FTIR spectra of adsorbed proteins are often found to be almost identical to the corresponding solution spectra indicating that the uptake into the brush did not alter the secondary structure of the proteins (Fig. 9). This was corroborated by a quantitative evaluation of the $\alpha$-helix and $\beta$-sheet fractions of adsorbed and dissolved BSA [81]. The obtained deviations are rather small and within the limit of experimental error. Even after the release of BSA from the PAA brush by raising the ionic strength of the solution, the FTIR analysis showed an intact native secondary structure of BSA. Hence, PAA brushes allow for a mild immobilization of proteins in large amounts.

For comparison, proteins were also studied at SPB particles carrying PSS chains. In this case, hydrophobic interactions will contribute in a major way to the uptake of the proteins. As a result, only a small portion of BSA can be released at high ionic strength. Furthermore, conformational changes of BSA occur, when this protein is adsorbed at SPB particles with PSS chains [81]. While this finding can be explained by the hydrophobic nature of PSS and the flexible structure of BSA [83], other globular proteins, such as $\beta$-lactoglobulin (BLG) or ribonuclease A (RNase A), maintained their native secondary structure within PSS brushes [81]. BLG and RNase A are considered as "robust" proteins [84]. These two proteins can also be quantitatively re-liberated from PSS brushes. Hence, the protein itself plays a decisive role. It is noted that the generally observed preservation of the secondary structure of proteins at polyelectrolyte brushes is in accordance with a high catalytic activity of enzymes that are adsorbed at spherical or planar polyelectrolyte brushes [71, 85-88]. It becomes thus evident that entrapment into polyelectrolyte brushes presents a very mild way of immobilizing proteins which circumvents denaturation that may easily occur on solid surfaces. 
Fig. 8 Secondary structures of some proteins according to their crystal structure. From left to right, lysozyme, ribonuclease $\mathrm{A}$ (RNase A), and bovine hemoglobin $(\mathrm{BHb})$. The latter is composed of two pairs of nonidentical $\alpha$-helix-rich subunits with tetrahedral arrangement. The images were prepared with Chimera 1.10.2 using PDB IDs 1LYZ, 1C9X, and 2DN2
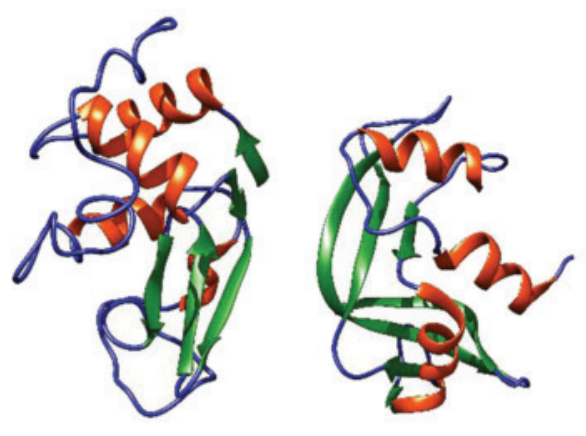

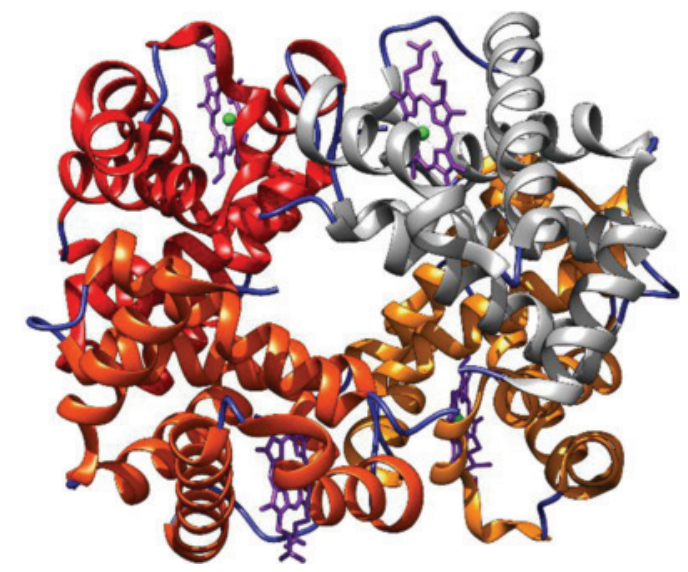

To further study the effect of polyelectrolyte brushes on the conformation of proteins, thermal unfolding is a crucial test. RNase A is a frequently studied model system for protein folding (Fig. 8). Its amino acid sequence and 3D structure are wellknown [89]. An intriguing feature of this protein is its ability to refold into its native conformation after thermal unfolding, when it is free in solution. Although many other proteins also unfold reversibly at low concentration, the formation of intermolecular $\beta$-structures can prevent refolding after thermal denaturation at higher concentrations. In contrast, disulfide bonds locally preserve some ordered structure of RNase A even in the unfolded state thus preventing efficiently inter- and intramolecular $\beta$-structures [90]. RNase A was adsorbed at SPB particles at $\mathrm{pH}$ 9.3, which is close to its isoelectric point of 9.6 [91]. This provides a high loading with protein without impeding the colloidal stability of the suspension. For comparison, folding studies were also performed on RNase A in solution. In Fig. 10, thermal unfolding and refolding of the protein upon heating to $75^{\circ} \mathrm{C}$ and cooling back to $25^{\circ} \mathrm{C}$ is monitored via the IR absorption at $1643 \mathrm{~cm}^{-1}$ [91]. Furthermore, the wavenumber shift of the amide I peak and the fractions of $\alpha$-helical and $\beta$-sheet structures were recorded with temperature. All data confirm that the thermal unfolding of RNase A is highly reversible, when the protein is free in solution (Fig. 10), in agreement with a simple two-state model [92]. The unfolding is mainly characterized by a decrease of $\beta$-sheet content which is compensated by the
Fig. 9 ATR-FTIR spectra of proteins adsorbed at a planar PAA brush (dotted lines) and transmission FTIR spectra of the same proteins in solution (solid lines) at $\mathrm{pD}=7.4$ and $20^{\circ} \mathrm{C}$. Reproduced with permission from Ref. [82]. Copyright 2009, American Chemical Society
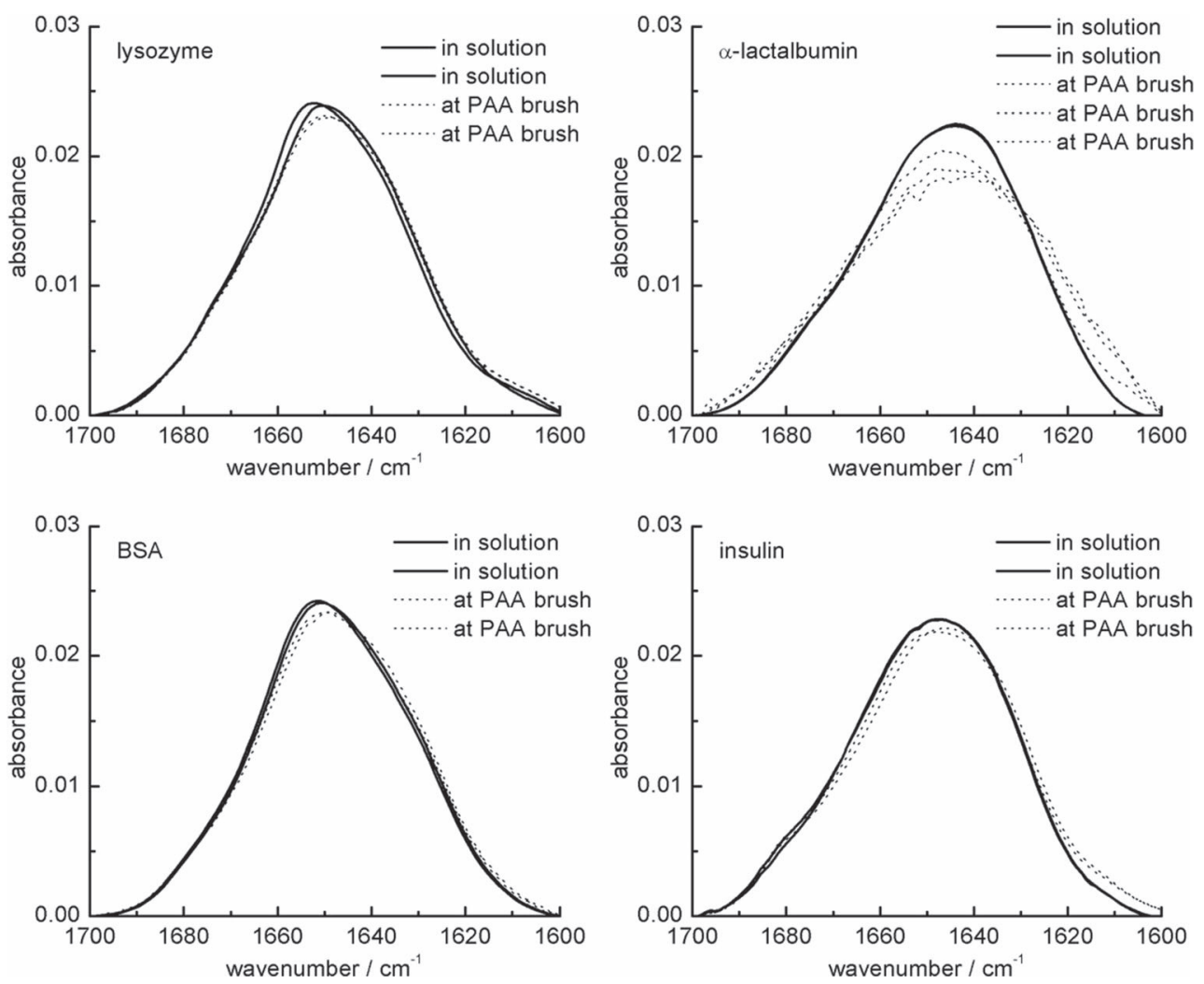


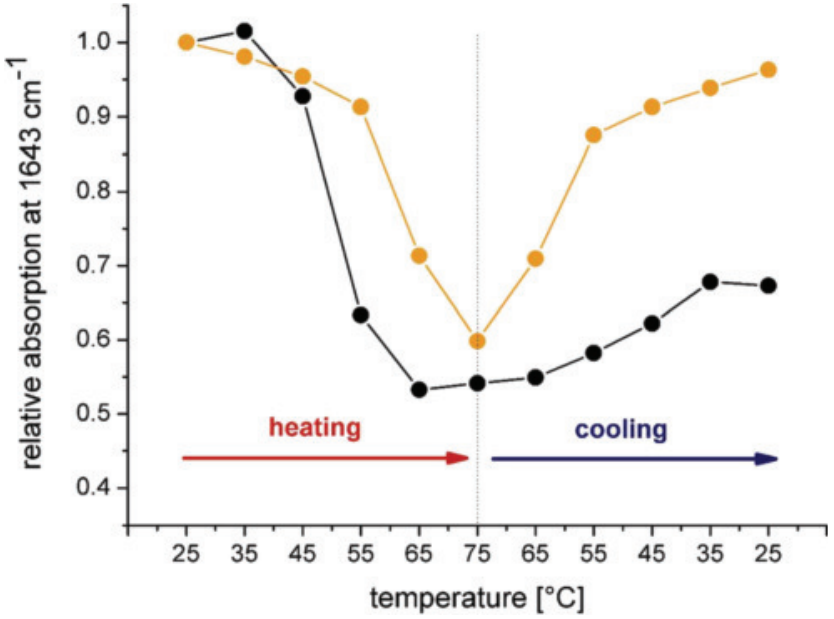

Fig. 10 Thermal unfolding of RNase A (pH 9.3): The change in the IR absorption at $1643 \mathrm{~cm}^{-1}$ (maximum of the amide I band of native RNase A) reflects the decrease in $\alpha$-helical and $\beta$-sheet structure during thermal unfolding (upon heating from $25^{\circ} \mathrm{C}$ to $75^{\circ} \mathrm{C}$ ) and reformation of these elements upon cooling (back to $25^{\circ} \mathrm{C}$ ). The course of the absorption demonstrates that the unfolding of native RNase A in solution (orange symbols) is fully reversible. When embedded into SPB, the protein unfolds at lower temperatures (black symbols). Moreover, it can only partially refold into its native conformation upon cooling. Adapted from Ref. [91] with permission. Copyright 2005, Wiley-VCH Verlag, Weinheim, Germany

formation of turns rather than random coil structures. Thermal unfolding of free RNase A is observed at $62-63{ }^{\circ} \mathrm{C}$, in agreement with earlier studies [93], and characterized by a van't Hoff enthalpy in the range of $420-430 \mathrm{~kJ} \mathrm{~mol}^{-1}$.

Upon adsorption at SPB particles with PSS chains at room temperature, the secondary structure of RNase A was not found to be altered significantly. However, the secondary structure of thermally unfolded RNase $\mathrm{A}$ at $75^{\circ} \mathrm{C}$ is somewhat different in the adsorbed state as compared to the free state in solution [91]. Within the brush, the $\alpha$-helical structure is lacking, whereas the $\beta$-sheet structure is partially preserved. Adsorbed RNase A already unfolds at $50{ }^{\circ} \mathrm{C}$ (Fig. 10) with a van't Hoff enthalpy change being lowered by almost $50 \%$. Notably, the protein cannot refold into its native conformation upon cooling within the polyelectrolyte brush (Fig. 10). This irreversibility of unfolding inside the polyelectrolyte brush layer points to the nature of adsorption, which is brought about by positive patches on the surface of the protein (Fig. 5). Thermal unfolding helps to optimize the interaction of these binding sites with the polyelectrolyte chains, which in turn tightens the binding of the protein.

It is noted that similar investigations have been made with nonbrush systems, where electrostatic interactions between a polymer and a protein are dominating, such as polyelectrolyte multilayers [94] and water-soluble polyelectrolyte complexes [95, 96].

Finally, a protein of higher structural complexity has also been studied in terms of adsorption at SPB particles with PSS chains: bovine hemoglobin $(\mathrm{BHb})$. It is a tetrameric protein (Fig. 8) and tends to disassemble into its subunits at low $\mathrm{pH}$ or high ionic strength [97]. Hence, disintegration of $\mathrm{BHb}$ might take place within dense polyacid brushes where the $\mathrm{pH}$ is lowered and the ionic strength is increased due to the confined counterions. Hemoglobin plays a central role in the storage of oxygen in vertebrates. For this reason, the protein has received considerable interest as a substitute for red blood cells [98]. However, direct application may cause side effects, such as renal toxicity or vasoconstriction [99]. One solution is the immobilization of the protein onto suitable transport vehicles [100].

The adsorption of BHb on SPB was studied using a combination of FTIR spectroscopy and small angle X-ray scattering (SAXS), because this provides insights into both secondary structure and localization of the adsorbed protein (the latter is discussed in the subsequent section) [101]. In Fig. 11, the amide I band in the FTIR spectrum of BHb is shown that was measured under different conditions. Free in solution, the high $\alpha$ helical content of the secondary structure is evident by a strong absorption centered at $1655 \mathrm{~cm}^{-1}$. However, marked structural changes are observed upon adsorption of the protein at the PSS brush. The content of $\alpha$-helical structure was reduced to its half, as compared to that of the native protein. Hydrophobic interactions of the protein with the PS core and the PSS chains of the SPB might cause the loss of helical structure. Moreover, $\beta$-sheet structure, which is absent in native $\mathrm{BHb}$, was formed upon adsorption. It is known that association among protein molecules can come along with the formation of intermolecular $\beta$ sheets. This mechanism, which is referred to as " $\beta$-aggregation," can be induced by hydrophobic interactions [102]. In the present case, $\beta$-aggregation could be triggered by the dense packing of the protein near to the hydrophobic PS core.

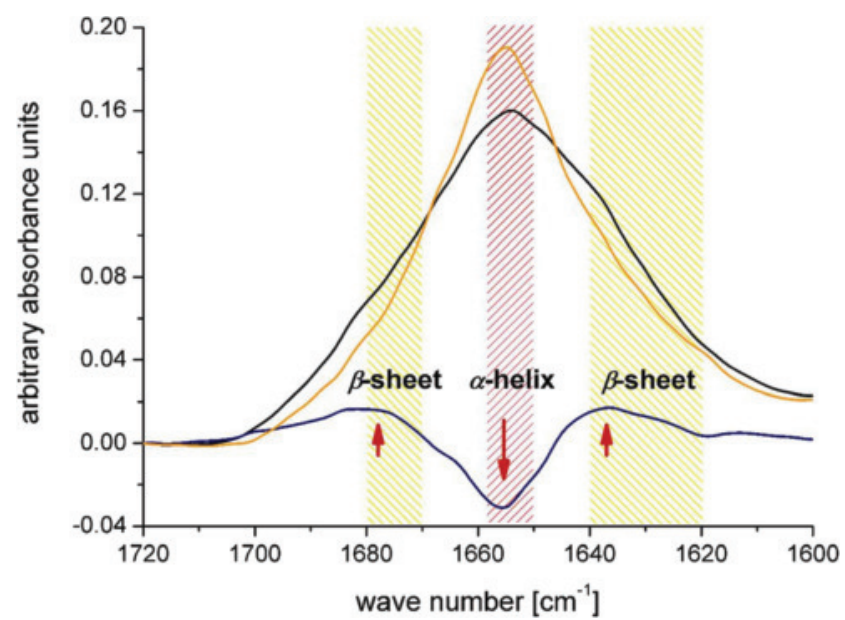

Fig. 11 IR absorption in the amide I region of free $\mathrm{BHb}$ in solution (orange line) and adsorbed BHb (black line) after subtracting the absorption of the supporting SPB. The difference spectrum (blue line) reflects conformational changes that stem from the interaction with the colloidal support. The highlighted areas are indicative for specific secondary structure elements. Uptake of $\mathrm{BHb}$ leads to a marked decrease in $\alpha$-helicity. Moreover, the difference spectrum reveals the formation of $\beta$-sheet elements that are absent in the native protein 


\section{Local distribution of proteins in polyelectrolyte brushes monitored by X-ray and neutron scattering}

Using scattering techniques, such as small-angle X-ray scattering (SAXS) and neutron reflectometry, density profiles across a polyelectrolyte brush with or without embedded protein can be obtained [22, 60,71, 101,103-105]. There is no atomic resolution, but the profiles show structural details on the nm-scale. Considering that polyelectrolyte brushes have a thickness on the order of several tens of nanometers and proteins have diameters of a few nanometers, detailed structural information about the polyelectrolyte brush in terms of thickness and density and about the local distribution of the protein molecules inside the polyelectrolyte brush is available. In the case of X-rays, electron densities are obtained. Alternatively, scattering of neutrons yields neutron scattering length densities that reflect the nature of the atomic nuclei. Thus, contrast variation can easily be achieved by deuteration of sample components or simply by $\mathrm{H}_{2} \mathrm{O}-\mathrm{D}_{2} \mathrm{O}$ exchange.

Applying SAXS to study an SPB sample with adsorbed protein, there is sufficient contrast, i.e., difference in electron densities, between the PS core and the polyelectrolyte shell $[103,104]$. Furthermore, proteins like BHb that bind metal ions show an excellent contrast to water. Thus, the local distribution of BHb in SPB can be determined with high spatial resolution by SAXS [101]. The uptake of the protein increases the electron density within the brush layer, which can be monitored by an increase in scattering intensity and a shift of the intensity maxima to smaller scattering vectors. By analyzing the SAXS data, the radial excess electron densities are obtained which reflect the distribution of $\mathrm{BHb}$ throughout the brush, which is illustrated in Fig. 12. Here, SPB particles with PSS chains were used. It is evident that the protein density parallels the density of the brush with a maximum protein concentration close to the PS core of the SPB particles. This local distribution of $\mathrm{BHb}$ can be attributed in part to hydrophobic interactions between the PS core and the protein. Close to the PS core, the protein is also exposed to the lowest $\mathrm{pH}$ and the highest ionic strength within the brush. However, the majority of the protein $(\sim 70 \%)$ is found closely correlated with the PSS chains documenting the binding of the protein by the PSS chains of the SPB particles. Apparently, BHb deeply penetrates the polyelectrolyte brush, albeit prepared with high grafting density.

SAXS studies of other proteins, such as BSA and RNase A, adsorbing at SPB particles did not show a protein accumulation in the innermost part of the brush [103]. Moreover, no significant change of their secondary structures upon adsorption was observed. In contrast, FTIR data of adsorbed $\mathrm{BHb}$ (Fig. 11) indicate some conformational changes inside the polyelectrolyte brush. The SAXS data of BHb suggest that the tetrameric protein also disassembles at least partially into

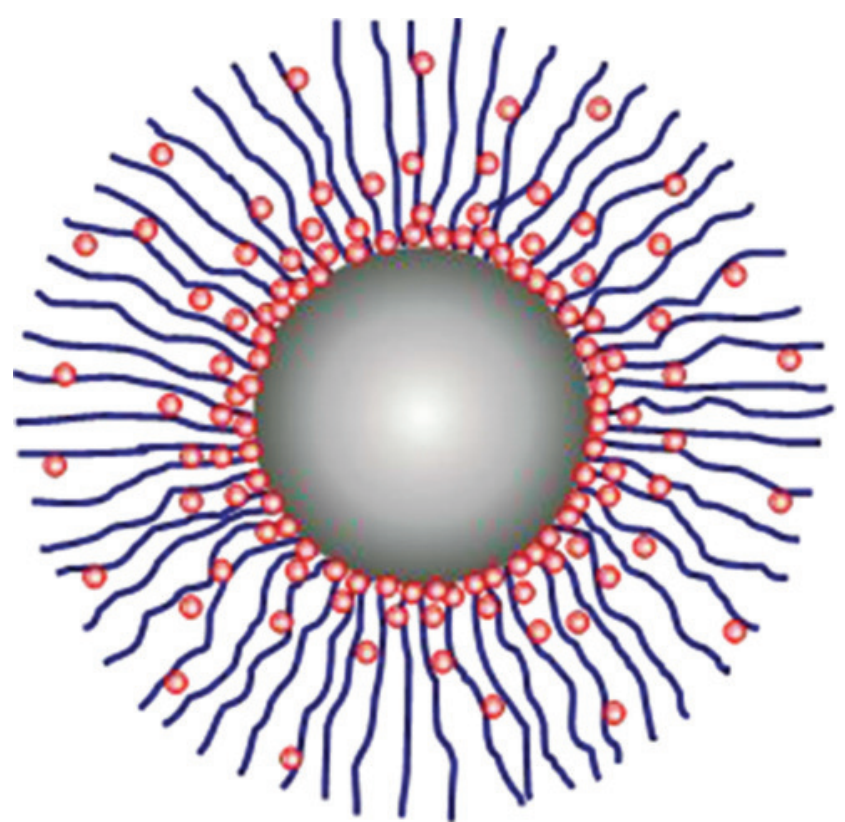

Fig. 12 Representation of $\mathrm{BHb}$ adsorption onto a spherical PSS brush: The dimensions of the brush particles are to scale. The distribution of the protein molecules within the brush layer was derived from the radial distribution of the excess electron density as obtained from SAXS measurements. Reproduced with permission from Ref. [101]. Copyright 2007, American Chemical Society

its subunits when entering the PSS brush. This will facilitate diffusion through the brush resulting in a preferential accumulation near the hydrophobic PS core, which presents the microenvironment with the lowest $\mathrm{pH}$ and highest density of counterions. Furthermore, the subunits might have a lower conformational stability inside the PSS brush, whereas the disassembly of $\mathrm{BHb}$ into subunits does hardly change the secondary structure, when the protein is dissolved in solution at low $\mathrm{pH}$ and high ionic strength.

In Fig. 13, volume fraction profiles across a planar PAA brush are shown. These data were obtained using neutron reflectometry making use of contrast variation [60]. The supporting PS film was fully deuterated (dPS), and $\mathrm{D}_{2} \mathrm{O}$ was used as the solvent. In this way, a huge contrast to the PAA chains and any adsorbing protein is created relative to dPS and $\mathrm{D}_{2} \mathrm{O}$, and the protein can be detected with high sensitivity. The profiles in Fig. 13 indicate that the protein $\alpha$-lactalbumin $(\alpha \mathrm{LA})$ with a negative net charge is deeply penetrating the like-charged PAA brush. Because of the planar geometry, the density of the PAA chains is more uniform across the brush layer as compared to the SPB particles. The measured volume fraction profiles clearly show that the protein is located where the PAA chains have the highest density suggesting a strong interaction. No accumulation of the protein at the surface of the dPS film is observed. Hence, structural studies using scattering techniques like SAXS or neutron reflectometry confirm the adsorption mechanism discussed above, where the driving force of protein adsorption at a polyelectrolyte 


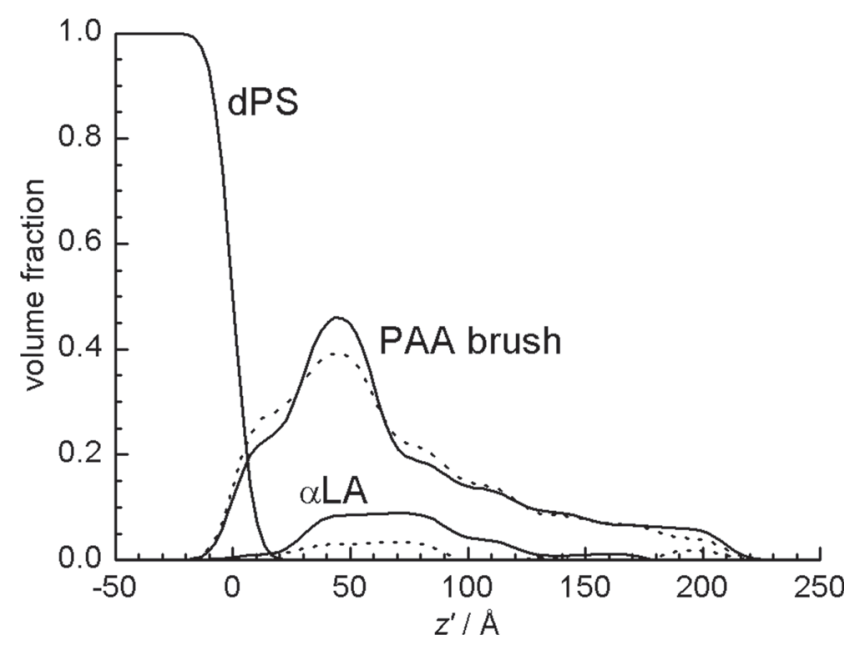

Fig. 13 Volume fraction profiles through a planar PAA brush with adsorbed $\alpha$ LA. The brush is supported by a deuterated poly(styrene) (dPS) film and is equilibrated in an aqueous $\alpha$ LA solution. The data were obtained in a neutron reflectivity study. Reproduced from Ref. [60] with permission from the PCCP Owner Societies

brush is based on the protein-polyelectrolyte chain interactions via a release of counterions.

\section{Conclusion}

Proteins bound to mesoscopic supports are much easier to handle than proteins in solution. This can be accomplished by incorporating them into polyelectrolyte brushes. These can be grafted to PS core particles, forming so-called spherical polyelectrolyte brushes (SPB), or to planar PS films. In both cases, the polyelectrolyte brushes directly adsorb considerable amounts of proteins from solution as long as the concentration of added salt is kept low. On the other hand, raising the ionic strength above a threshold allows for triggering the release of the protein molecules from the polyelectrolyte brushes composed of PAA or PSS chains. There is convincing theoretical and experimental evidence that the binding of proteins to likecharged polyelectrolyte brushes is mainly driven by a release of counterions.

So far, the adsorption of proteins at spherical or planar polyelectrolyte brushes has been studied using a series of experimental techniques. Very powerful methods to determine the structure of protein-polyelectrolyte brush systems include cryo-TEM, FTIR spectroscopy, SAXS, and neutron reflectometry. For example, imaging SPB using cryo-TEM clearly shows a close correlation of the protein molecules and the polyelectrolyte chains. A deep penetration of proteins into polyelectrolyte brushes, even under net electrostatic repulsion, was also inferred from SAXS and neutron reflectometry. The secondary structure of many different proteins, which are embedded in polyelectrolyte brushes, has been studied by FTIR spectroscopy. Generally, the polyelectrolyte brush environment has little or no measurable effect on the secondary structures of the proteins. However, deviations from the solution behavior have been observed, when a protein is thermally unfolded inside a brush, and in the case of complex proteins with quaternary structure, such as hemoglobin. Thus, some care has to be taken, when proteins of weak conformational stability are adsorbed at a polyelectrolyte brush or when they are exposed to denaturing conditions, such as elevated temperatures.

To summarize, the immobilization of proteins at polyelectrolyte brushes provides a promising tool to use proteins in biomedical or biotechnological applications. The preservation of the protein native structure inside the polyelectrolyte brushes and the control over the degree of adsorption by adjusting the ionic strength of the solution are of unmatched advantage.

Acknowledgments Financial support from the Deutsche Forschungsgemeinschaft (DFG Forschergruppe 1979, SFB1214/A10) is gratefully acknowledged.

\section{Compliance with ethical standards}

Conflict of interest The authors declare that they have no conflicts of interest.

\section{References}

1. Shen L, Zhu J (2016) Heterogeneous surfaces to repel proteins. Adv Colloid Interf Sci 228:40-54. https://doi.org/10.1016/j.cis. 2015.11.008

2. Rabe M, Verdes D, Seeger S (2011) Understanding protein adsorption phenomena at solid surfaces. Adv Colloid Interf Sci 162: 87-106. https://doi.org/10.1016/j.cis.2010.12.007

3. Malmsten M (2003) Biopolymers at interfaces, 2nd edn. Marcel Dekker, New York

4. Baszkin A, Norde W (2000) Physical chemistry of biological interfaces. Marcel Dekker, New York

5. Senaratne W, Andruzzi L, Ober CK (2005) Self-assembled monolayers and polymer brushes in biotechnology: current applications and future perspectives. Biomacromolecules 6:2427-2448. https://doi.org/10.1021/bm050180a

6. Mao C, Qiu Y, Sang H, Mei H, Zhu A, Shen J, Lin S (2004) Various approaches to modify biomaterial surfaces for improving hemocompatibility. Adv Colloid Interf Sci 110:5-17. https://doi. org/10.1016/j.cis.2004.02.001

7. Davey ME, O'Toole GA (2000) Microbial biofilms: from ecology to molecular genetics. Microbiol Mol Biol Rev 64:847-867. https://doi.org/10.1128/MMBR.64.4.847-867.2000

8. Tugulu S, Klok H-A (2008) Stability and nonfouling properties of poly(poly(ethylene glycol) methacrylate) brushes under cell culture conditions. Biomacromolecules 9:906-912. https://doi.org/ 10.1021/bm701293g

9. Holland NB, Qiu Y, Ruegsegger M, Marchant ME (1998) Biomimetic engineering of non-adhesive glycocalyx-like surfaces using oligosaccharide surfactant polymers. Nature 392:799-801. https://doi.org/10.1038/33894 
10. Krishnan S, Weinman CJ, Ober CK (2008) Advances in polymers for anti-biofouling surfaces. J Mater Chem 18:3405-3413. https:// doi.org/10.1039/B801491D

11. Chang Y, Liao S-C, Higuchi A, Ruaan R-C, Chu C-W, Chen W-Y (2008) A highly stable nonbiofouling surface with well-packed grafted zwitterionic polysulfobetaine for plasma protein repulsion. Langmuir 24:5453-5458. https://doi.org/10.1021/la800228c

12. Talbert JN, Goddard JM (2012) Enzymes on material surfaces. Colloids Surf B 93:8-19. https://doi.org/10.1016/j.colsurfb.2012. 01.003

13. Mateo C, Palomo JM, Fernandez-Lorente G, Guisan JM, Fernandez-Lafuente R (2007) Improvement of enzyme activity, stability and selectivity via immobilization techniques. Enzym Microb Technol 40:1451-1463. https://doi.org/10.1016/j. enzmictec.2007.01.018

14. Das S, Banik M, Chen G, Sinha S, Mukherjee R (2015) Polyelectrolyte brushes: theory, modelling, synthesis and applications. Soft Matter 11:8550-8583. https://doi.org/10.1039/ C5SM01962A

15. Psarra E, König U, Ueda Y, Bellmann C, Janke A, Bittrich E, Eichhorn K-J, Uhlmann P (2015) Nanostructured biointerfaces: nanoarchitectonics of thermoresponsive polymer brushes impact protein adsorption and cell adhesion. ACS Appl Mater Interfaces 7:12516-12529. https://doi.org/10.1021/am508161q

16. Whiting GL, Farhan T, Huck WTS (2004) Polymer brushes: towards applications. In: Advincula RC, Brittain WJ, Caster KC, Rühe J (eds) Polymer brushes: synthesis, characterization, applications. Wiley-VCH, Weinheim, pp 371-380. https://doi.org/10. 1002/3527603824.ch18

17. Xue C, Yonet-Tanyeri N, Brouette N, Sferrazza M, Braun PV, Leckband DE (2011) Protein adsorption on poly (Nisopropylacrylamide) brushes: dependence on grafting density and chain collapse. Langmuir 27:8810-8818. https://doi.org/10. 1021/la2001909

18. Burkert S, Bittrich E, Kuntzsch M, Müller M, Eichhorn K-J, Bellmann C, Uhlmann P, Stamm M (2010) Protein resistance of PNIPAAm brushes: application to switchable protein adsorption. Langmuir 26:1786-1795. https://doi.org/10.1021/la902505q

19. Halperin A, Kröger M (2011) Collapse of Thermoresponsive brushes and the tuning of protein adsorption. Macromolecules 44:6986-7005. https://doi.org/10.1021/ma201006h

20. Kusumo A, Bombalski L, Lin Q, Matyjaszewski K, Schneider JW, Tilton RD High capacity, charge-selective protein uptake by polyelectrolyte brushes. Langmuir 23:4448-4454. https://doi.org/10. 1021/la063660b

21. Uhlmann P, Houbenov N, Brenner N, Grundke K, Burkert S, Stamm M (2007) In-situ investigation of the adsorption of globular model proteins on stimuli-responsive binary polyelectrolyte brushes. Langmuir 23:57-64. https://doi.org/10.1021/la061557g

22. Czeslik C, Jackler G, Hazlett T, Gratton E, Steitz R, Wittemann A, Ballauff M (2004) Salt-induced protein-resistance of polyelectrolyte brushes studied by fluorescence correlation spectroscopy and neutron reflectivity. Phys Chem Chem Phys 6:5557-5563. https:// doi.org/10.1039/B410805A

23. Wittemann A, Haupt B, Ballauff M (2003) Adsorption of proteins on spherical polyelectrolyte brushes in aqueous solution. Phys Chem Chem Phys 5:1671-1677. https://doi.org/10.1039/ B300607G

24. Hollmann O, Czeslik C (2006) Characterization of a planar PAA brush as a materials coating for controlled protein immobilization. Langmuir 22:3300-3305. https://doi.org/10.1021/la053110y

25. Wittemann A, Haupt B, Ballauff M (2007) Controlled release of proteins bound to spherical polyelectrolyte brushes. Z Phys Chem 221:113-126. https://doi.org/10.1524/zpch.2007.221.1.113

26. Lu Y, Wittemann A, Ballauff M (2009) Supramolecular structures generated by spherical polyelectrolyte brushes and their application in catalysis. Macromol Rapid Commun 30:806-815. https://doi.org/10.1002/marc.200800789

27. Winter R, Noll F, Czeslik C (2011) Methoden der Biophysikalischen Chemie, 2nd edn. Vieweg+Teubner, Wiesbaden

28. Drenth J (1999) Principles of protein X-ray crystallography. Springer, New York

29. Wüthrich K (2001) The way to NMR structures of proteins. Nature Struct Biol 8:923-925. https://doi.org/10.1038/nsb1101-923

30. Surewicz WK, Mantsch HH, Chapman D Determination of protein secondary structure by Fourier transform infrared spectroscopy: a critical assessment. Biochemistry 32:389-394. https://doi. org/10.1021/bi00053a001

31. Pelton JT, McLean LR (2000) Spectroscopic methods for analysis of protein secondary structure. Anal Biochem 277:167-176. https://doi.org/10.1006/abio.1999.4320

32. Fabian H, Schultz CP (2000) Fourier transform infrared spectroscopy in peptide and protein analysis. In: Meyers RA (ed) Encyclopedia of analytical chemistry. Wiley, Chichester. https:// doi.org/10.1002/9780470027318.a1612

33. Greenfield N, Fasman GD (1969) Computed circular dichroism spectra for the evaluation of protein conformation. Biochemistry 8:4108-4116. https://doi.org/10.1021/bi00838a031

34. Urry DW (1972) Protein conformation in biomembranes: optical rotation and absorption of membrane suspensions. Biochim Biophys Acta 265:115-168. https://doi.org/10.1016/03044157(72)90021-4

35. Dousseau F, Pézolet M (1990) Determination of the secondary structure content of proteins in aqueous solutions from their amide I and amide II infrared bands. Comparison between classical and partial least-squares methods. Biochemistry 29:8771-8779. https://doi.org/10.1021/bi00489a038

36. Goormaghtigh E, Raussens V, Ruysschaert JM (1999) Attenuated total reflection infrared spectroscopy of proteins and lipids in biological membranes. Biochim Biophys Acta 1422:105-185. https://doi.org/10.1016/S0005-2736(03)00167-6

37. Byler DM, Susi H (1986) Examination of the secondary structure of proteins by deconvolved FTIR spectra. Biopolymers 25:469487. https://doi.org/10.1002/bip.360250307

38. Eftink MR (1994) The use of fluorescence methods to monitor unfolding transitions in proteins. Biophys $\mathrm{J}$ 66:482-501. https:// doi.org/10.1016/S0006-3495(94)80799-4

39. LeVine III H (1993) Thioflavine $\mathrm{T}$ interaction with synthetic Alzheimer's disease $\beta$-amyloid peptides: detection of amyloid aggregation in solution. Protein Sci 2:404-410. https://doi.org/ 10.1002/pro.5560020312

40. Alcala JR, Gratton E, Prendergast FG (1987) Interpretation of fluorescence decays in proteins using continuous lifetime distributions. Biophys J 51:925-936. https://doi.org/10.1016/S00063495(87)83420-3

41. Lakowicz JR, Maliwal BP, Cherek H, Balter A (1983) Rotational freedom of tryptophan residues in proteins and peptides. Biochemistry 22:1741-1752. https://doi.org/10.1021/ bi00277a001

42. Elson EL (2011) Fluorescence correlation spectroscopy: past, present, future. Biophys J 101:2855-2870. https://doi.org/10. 1016/j.bpj.2011.11.012

43. Hess ST, Huang S, Heikal AA, Webb WW (2002) Biological and chemical applications of fluorescence correlation spectroscopy: a review. Biochemistry 41:697-705. https://doi.org/10.1021/ bi0118512

44. Axelrod D, Burghardt TP, Thompson NL (1984) Total internal reflection fluorescence. Ann Rev Biophys Bioeng 13:247-268. https://doi.org/10.1146/annurev.bb.13.060184.001335

45. Blanchett CE, Svergun DI (2013) Small-angle X-ray scattering on biological macromolecules and nanocomposites in solution. Ann 
Rev Phys Chem 64:37-54. https://doi.org/10.1146/annurevphyschem-040412-110132

46. Wei Z, Prescott SW (2015) Scattering approaches to probing surface layers under confinement. Curr Opin Colloid Interface Sci 20: 253-260. https://doi.org/10.1016/j.cocis.2015.09.001

47. Russell TP (1990) X-ray and neutron reflectivity for the investigation of polymers. Mater Sci Rep 5:171-271. https://doi.org/10. 1016/S0920-2307(05)80002-7

48. Anikin K, Röcker C, Wittemann A, Wiedenmann J, Ballauff M, Nienhaus GU (2005) Polyelectrolyte-mediated protein adsorption: fluorescent protein binding to individual polyelectrolyte nanospheres. J Phys Chem B 109:5418-5420. https://doi.org/10. 1021/jp0506282

49. Mei Y, Wittemann A, Sharma G, Ballauff M, Koch T, Gliemann H, Horbach J, Schimmel T (2003) Engineering the interaction of latex spheres with charged surfaces: AFM investigation of spherical polyelectrolyte brushes on mica. Macromolecules 36:34523456. https://doi.org/10.1021/ma0258399

50. Wittemann A, Drechsler M, Talmon Y, Ballauff M (2005) High elongation of polyelectrolyte chains in the osmotic limit of spherical polyelectrolyte brushes: a study by cryogenic transmission electron microscopy. J Am Chem Soc 127:9688-9689. https:// doi.org/10.1021/ja0513234

51. Cinar S, Czeslik C (2015) Secondary structure and folding stability of proteins adsorbed on silica particles - pressure versus temperature denaturation. Colloids Surf B 129:161-168. https://doi. org/10.1016/j.colsurfb.2015.03.043

52. Sethuraman A, Belfort G (2005) Protein structural perturbation and aggregation on homogeneous surfaces. Biophys J 88:13221333. https://doi.org/10.1529/biophysj.104.051797

53. Bentaleb A, Abele A, Haikel Y, Schaaf P, Voegel JC (1998) FTIRATR and radiolabeling study of the adsorption of ribonuclease A onto hydrophilic surfaces: correlation between the exchange rate and the interfacial denaturation. Langmuir 14:6493-6500. https:// doi.org/10.1021/la980537e

54. Kondo A, Oku S, Higashitani K (1991) Structural changes in protein molecules adsorbed on ultrafine silica particles. J Colloid Interface Sci 143:214-221. https://doi.org/10.1016/00219797(91)90454-G

55. Fröberg JC, Arnebrant T, McGuire J, Claesson PM (1998) Effect of structural stability on the characteristics of adsorbed layers of T4 lysozyme. Langmuir 14:456-462. https://doi.org/10.1021/ la970674w

56. Wertz CF, Santore MM (2002) Adsorption and reorientation kinetics of lysozyme on hydrophobic surfaces. Langmuir 18:11901199. https://doi.org/10.1021/la0108813

57. Schrinner M, Haupt B, Wittemann A (2008) A novel photoreactor for the production of electrosterically stabilised colloidal particles at larger scales. Chem Eng J 144:138-145. https://doi.org/10. 1016/j.cej.2008.07.018

58. Guo X, Ballauff M (2000) Spatial dimensions of colloidal polyelectrolyte brushes as determined by dynamic light scattering. Langmuir 16:8719-8726. https://doi.org/10.1021/la000319x

59. Ballauff M (2007) Spherical polyelectrolyte brushes. Prog Polym Sci 32:1135-1151. https://doi.org/10.1016/j.progpolymsci.2007. 05.002

60. Hollmann O, Steitz R, Czeslik C (2008) Structure and dynamics of $\alpha$-lactalbumin adsorbed at a charged brush interface. Phys Chem Chem Phys 10:1448-1456. https://doi.org/10.1039/B716264B

61. Wittemann A, Ballauff M (2006) Interaction of proteins with linear polyelectrolytes and spherical polyelectrolyte brushes in aqueous solution. Phys Chem Chem Phys 8:5269-5275. https://doi. org/10.1039/B609879G

62. Milner ST (1991) Polymer brushes. Science 251:905-914. https:// doi.org/10.1126/science.251.4996.905
63. Biesheuvel PM, Wittemann A (2005) A modified box model including charge regulation for protein adsorption in a spherical polyelectrolyte brush. Phys Chem B 109:4209-4214. https://doi. org/10.1021/jp0452812

64. Biesheuvel PM, Leermakers FAM, Cohen Stuart MA (2006) Selfconsistent field theory of protein adsorption in a non-Gaussian polyelectrolyte brush. Phys Rev E 73:011802. https://doi.org/10. 1103/PhysRevE.73.011802

65. de Vos WM, Leermakers FAM, de Keizer A, Cohen Stuart MA, Kleijn JM (2010) Field theoretical analysis of driving forces for the uptake of proteins by like-charged polyelectrolyte brushes: effects of charge regulation and patchiness. Langmuir 26:249259. https://doi.org/10.1021/la902079u

66. Leermakers FAM, Ballauff M, Borisov OV (2007) On the mechanism of uptake of globular proteins by polyelectrolyte brushes: a two-gradient self-consistent field analysis. Langmuir 23:39373946. https://doi.org/10.1021/la0632777

67. Yigit C, Kanduč M, Ballauff M, Dzubiella J (2017) Interaction of charged patchy protein models with like-charged polyelectrolyte brushes. Langmuir 33:417-427. https://doi.org/10.1021/acs. langmuir.6b03797

68. Xu X, Angioletti-Uberti S, Lu Y, Dzubiella J, Ballauff M (2019) Interaction of proteins with polyelectrolytes: comparison of theory to experiment. Langmuir 35:5373-5391. https://doi.org/10.1021/ acs.langmuir.8b01802

69. Henzler K, Haupt B, Lauterbach K, Wittemann A, Borisov O, Ballauff M (2010) Adsorption of $\beta$-lactoglobulin on spherical polyelectrolyte brushes: direct proof of counterion release by isothermal titration calorimetry. J Am Chem Soc 132:3159-3163. https://doi.org/10.1021/ja909938c

70. Walkowiak J, Lu Y, Gradzielski M, Zauscher S, Ballauff M (2019) Thermodynamic analysis of the uptake of a protein in a spherical polyelectrolyte brush. Macromol Rapid Commun 1900421. https://doi.org/10.1002/marc.201900421

71. Levin A, Erlkamp M, Steitz R, Czeslik C (2016) Volume profile of $\alpha$-chymotrypsin during adsorption and enzymatic reaction on a poly(acrylic acid) brush. Phys Chem Chem Phys 18:9070-9078. https://doi.org/10.1039/C6CP00843G

72. Levin A, Czeslik C (2018) Interaction of calmodulin with poly(acrylic acid) brushes: effects of high pressure, $\mathrm{pH}$-value and ligand binding. Colloids Surf B 171:478-484. https://doi.org/10.1016/j. colsurfb.2018.07.073

73. Luong TQ, Kapoor S, Winter R (2015) Pressure - a gateway to fundamental insights into protein solvation, dynamics, and function. Chem Phys Chem 16:3555-3571. https://doi.org/10.1002/ cphc. 201500669

74. Boonyaratanakornkit BB, Park CB, Clark DS (2002) Pressure effects on intra- and intermolecular interactions within proteins. Biochim Biophys Acta 1595:235-249. https://doi.org/10.1016/ S0167-4838(01)00347-8

75. Abe F, Kato C, Horikoshi K (1999) Pressure-regulated metabolism in microorganisms. Trends Microbiol 7:447-453. https://doi. org/10.1016/S0966-842X(99)01608-X

76. Hariharan R, Biver C, Russel WB (1998) Ionic strength effects in polyelectrolyte brushes: the counterion correction. Macromolecules 31:7514-7518. https://doi.org/10.1021/ma9718199

77. Korobko AV, Jesse W, Egelhaaf SU, Lapp A, van der Maarel JRC (2004) Do spherical polyelectrolyte brushes interdigitate? Phys Rev Lett 93:177801. https://doi.org/10.1103/PhysRevLett.93.177801

78. Matsen MW (2005) Effect of chain tilt on the interaction between brush-coated colloids. Macromolecules 38:4525-4530. https:// doi.org/10.1021/ma050362x

79. Jusufi A, Likos CN, Ballauff M (2004) Counterion distributions and effective interactions of spherical polyelectrolyte brushes. Colloid Polym Sci 282:910-917. https://doi.org/10.1007/s00396004-1129-9 
80. Rahmelow K, Hübner W (1996) Secondary structure determination of proteins in aqueous solution by infrared spectroscopy: a comparison of multivariate data analysis methods. Anal Biochem 241:5-13. https://doi.org/10.1006/abio.1996.0369

81. Wittemann A, Ballauff M (2004) Secondary structure analysis of proteins embedded in spherical polyelectrolyte brushes by FT-IR spectroscopy. Anal Chem 76:2831-2819. https://doi.org/10.1021/ ac0354692

82. Reichhart C, Czeslik C (2009) Native-like structure of proteins at a planar poly(acrylic acid) brush. Langmuir 25:1047-1053. https:// doi.org/10.1021/la802905s

83. Carter DC, Ho JX (1994) Structure of serum albumin. Adv Protein Chem 45:153-203. https://doi.org/10.1016/S0065-3233(08) 60640-3

84. Arai T, Norde W (1990) The behavior of some model proteins at solid-liquid interfaces 1 . Adsorption from single protein solutions. Colloids Surf 51:1-15. https://doi.org/10.1016/0166-6622(90) 80127-P

85. Haupt B, Neumann T, Wittemann A, Ballauff M (2005) Activity of enzymes immobilized in colloidal spherical polyelectrolyte brushes. Biomacromolecules 6:948-955. https://doi.org/10.1021/ bm0493584

86. Neumann T, Haupt B, Ballauff M (2004) High activity of enzymes immobilized in colloidal nanoreactors. Macromol Biosci 4:13-16. https://doi.org/10.1002/mabi.200300053

87. Levin A, Hartl A, Reiser O, Czeslik C (2019) High-pressure study of magnetic nanoparticles with a polyelectrolyte brush as carrier particles for enzymes. Colloids Surf B 182:110344. https://doi. org/10.1016/j.colsurfb.2019.110344

88. Reichhart C, Czeslik C (2010) A quantitative study of the enzymatic activity of horseradish peroxidase at a planar poly(acrylic acid) brush. Colloids Surf B 75:612-616. https://doi.org/10.1016/ j.colsurfb.2009.10.017

89. Raines RT (1998) Ribonuclease A. Chem Rev 98:1045-1066. https://doi.org/10.1021/cr960427h

90. Fabian H, Schultz C, Naumann D, Landt O, Hahn U, Saenger W (1993) Secondary structure and temperature-induced unfolding and refolding of ribonuclease $\mathrm{T}_{1}$ in aqueous solution. $\mathrm{J}$ Mol Biol 232:967-981. https://doi.org/10.1006/jmbi.1993.1442

91. Wittemann A, Ballauff M (2005) Temperature-induced unfolding of ribonuclease A embedded in spherical polyelectrolyte brushes. Macromol Biosci 5:13-20. https://doi.org/10.1002/mabi. 200400133

92. Neira JL, Rico M (1997) Folding studies on ribonuclease A, a model protein. Fold Des 2:R1-R11. https://doi.org/10.1016/ S1359-0278(97)00001-1

93. Von Hippel PH, Wong PH (1965) On the conformational stability of globular proteins: the effects of various electrolytes and nonelectrolytes on the thermal ribonuclease transition. J Biol Chem 240:3909-3923 http://www.jbc.org/content/240/10/3909.citation

94. Schwinté P, Ball V, Szalontai B, Haikel Y, Voegel J-C, Schaaf P (2002) Secondary structure of proteins adsorbed onto or embedded in polyelectrolyte multilayers. Biomacromolecules 3:11351143. https://doi.org/10.1021/bm025547f

95. Ivinova ON, Izumrudov VA, Muronetz VI, Galaev IY, Mattiasson B (2003) Influence of complexing polyanions on the thermostability of basic proteins. Macromol Biosci 3:210-215. https://doi. org/10.1002/mabi.200390024

96. Martin N, Ma D, Herbet A, Boquet D, Winnik FM, Tribet C (2014) Prevention of thermally induced aggregation of IgG antibodies by noncovalent interaction with poly(acrylate) derivatives. Biomacromolecules 15:2952-2962. https://doi.org/10.1021/ bm5005756

97. Rossi-Fanelli A, Antonini E, Caputo A (1964) Hemoglobin and myoglobin. Adv Protein Chem 19:73-222. https://doi.org/10. 1016/S0065-3233(08)60189-8
98. Goodrich RP, Sowemino-Coker SO, Weinstein R (1994) Advances in erythrocyte preservation and hemoglobin substitutes. Curr Opin Hematol 1:162-169

99. Arifin DR, Palmer AF (2003) Determination of size distribution and encapsulation efficiency of liposome-encapsulated hemoglobin blood substitutes using asymmetric flow field-flow fractionation coupled with multi-angle static light scattering. Biotechnol Prog 19:1798-1811. https://doi.org/10.1021/bp034120x

100. Kuznetsova NP, Mishaeva RN, Gudkin LR (1997) Microdisperse form of immobilized hemoglobin modeling the erythrocytes. Artif Cells Blood Subs Immob Biotechnol 25:463-472. https://doi.org/ 10.3109/10731199709118936

101. Henzler K, Wittemann A, Breininger E, Ballauff M, Rosenfeldt S (2007) Adsorption of bovine hemoglobin onto spherical polyelectrolyte brushes monitored by small-angle X-ray scattering and Fourier transform infrared spectroscopy. Biomacromolecules 8: 3674-3681. https://doi.org/10.1021/bm700953e

102. Kato A, Tagaki T (1998) Formation of intermolecular $\beta$-sheet structure during heat denaturation of ovalbumin. J Agric Food Chem 36:1156-1159. https://doi.org/10.1021/jf00084a007

103. Rosenfeldt S, Wittemann A, Ballauff M, Breininger E, Bolze J, Dingenouts N (2004) Interaction of proteins with spherical polyelectrolyte brushes in solution as studied by small-angle X-ray scattering. Phys Rev E 70:061403. https://doi.org/10.1103/ PhysRevE.70.061403

104. Henzler K, Rosenfeldt S, Wittemann A, Harnau L, Finet S, Narayanan T, Ballauff M (2008) Directed motion of proteins along tethered polyelectrolytes. Phys Rev Lett 100:158301. https://doi.org/10.1103/PhysRevLett.100.158301

105. Evers F, Reichhart C, Steitz R, Tolan M, Czeslik C (2010) Probing adsorption and aggregation of insulin at a poly(acrylic acid) brush. Phys Chem Chem Phys 12:4375-4382. https://oi.org/10.1039/ B925134K

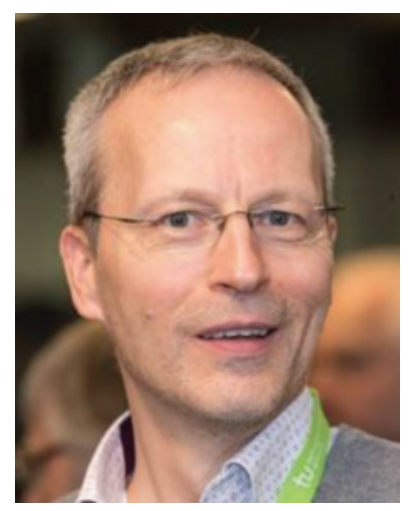

Claus Czeslik has been a professor of physical chemistry at TU Dortmund University, Germany, since 2011. He studied chemistry at Ruhr-Universität Bochum, Germany, and received his $\mathrm{PhD}$ degree in 1997 from TU Dortmund University. He completed postdoctoral research in physical chemistry at the University of Illinois at UrbanaChampaign, and at $\mathrm{TU}$ Dortmund University, where he received the Venia Legendi in 2006. His current research focuses on the structure and functionality of protein-polymer interfaces. Prof. Ballauff inspired and guided him to study the interaction of proteins with polyelectrolyte brushes, with many meetings in Karlsruhe, Bayreuth, Berlin and Dortmund where new ideas were shared. The exciting research on protein-polyelectrolyte brush systems has led to several publications co-authored by M. Ballauff and C. Czeslik and to the joint organization of the Bunsen colloquium on protein adsorption in 2006. 


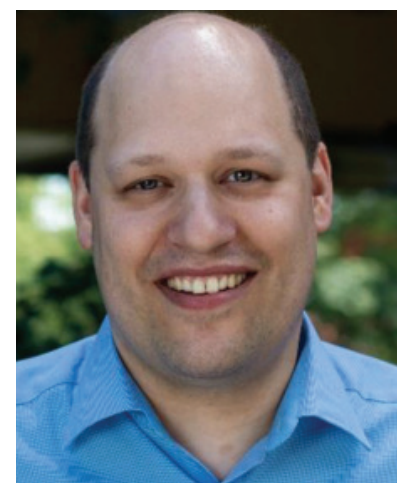

Alexander Wittemann has been a professor of colloid chemistry at the University of Konstanz,

Germany, since 2011. He studied chemistry at the University of Karlsruhe (TH), Germany. He was awarded his doctorate under the supervision of Prof. Matthias Ballauff in 2004. In the year before, he followed M. Ballauff to the University of Bayreuth. After postdoctoral research in polymer science at McGill University, Montreal, Canada, he returned to Bayreuth, where he received his habilitation in physical chemistry in 2011. His current research focuses on nanoparticle assemblies. As a supervisor and mentor M. Ballauff was truly a permanent source of inspiration for A. Wittemann. The latter takes this opportunity to thank M. Ballauff for all the guidance, advice, help, and support over many years. Matthias Ballauff also brought the two authors together and laid the fundament for a fruitful collaboration, out of which also this article dedicated to him arose. 